ENSAYO

\title{
BENEVOLENCIA Y EDUCACIÓN PÚBLICA EN ADAM SMITH*
}

\author{
María Elton
}

Una cierta vulgarización del pensamiento de Adam Smith ha puesto el acento en la importancia del interés por sí mismo en la sociedad comercial, con detrimento de la benevolencia. El interés por sí mismo sería no moral y la benevolencia moral. En este artículo se sostiene, sin embargo, que si profundizamos en su filosofía expuesta en La Teoría de los Sentimientos Morales, que se encuentra en el trasfondo de La Riqueza de las Naciones, se advierte que el interés por sí mismo puede ser virtuoso, llegando a ser una prudencia inferior, y que la benevolencia es importante también para la sociedad comercial, para corregir los desequilibrios que aparecen en su desarrollo. La benevolencia no sólo sería compatible con la prudencia inferior en La Riqueza de las Naciones, sino también a veces exigible. Adam Smith admite que el Estado no sólo debe proteger la justicia conmutativa entre los individuos, sino también exigir un cierto grado de

María Elton. Doctora en Filosofía por la Universidad de Navarra. Profesora de ética y filosofía moral moderna en el Instituto de Filosofía de la Universidad de los Andes (Santiago). Autora de El Amor Puro de Fénelon en el Contexto del Pensamiento Moderno (Eunsa, Pamplona, 1989) y El Derecho de los Padres a la Educación de sus Hijos (Eunsa, Pamplona, 1982) y de numerosos artículos en revistas especializadas.

* Este escrito es resultado del proyecto de investigación $N^{\circ}$ 1030571, financiado por Fondecyt (Fondo de Ciencia y Tecnología de Chile).

Para las abreviaciones y referencias de las obras de Adam Smith, véase sección a) de la bibliografía al final del artículo. Las citas textuales de las obras de Smith en este escrito han sido traducidas por mí. 
justicia distributiva por parte de la sociedad, para corregir ciertas desigualdades fundamentales, como la que proviene de la división del trabajo: la deshumanización de los trabajadores comunes. El sistema de la libertad natural depende entonces — se sugiere en este ensayo- de la educación moral y política de todos los individuos que conforman una sociedad.

\section{Introducción}

$\mathrm{U}_{\mathrm{n}}$ no de los problemas de la sociedad actual es la escasa participación política de los ciudadanos, que en su mayoría han dejado esas tareas en manos de los políticos profesionales, quienes serían sus representantes. Elio Gallego argumenta lúcidamente en un escrito reciente acerca de las causas de ese fenómeno social ${ }^{1}$. Entre ellas se encontraría, según Gallego, la mudanza que se ha producido desde el siglo XVIII hacia un modelo de sociedad comercial que busca la opulencia y el bienestar, en la cual los individuos emplean su tiempo en atender los negocios propios más que la actividad política. Gallego se refiere al abate Siéyès, quien afirma que "los pueblos europeos modernos se parecen muy poco a los antiguos. Lo fundamental entre nosotros es el comercio, la agricultura, las fábricas, etc. El deseo de riquezas parece transformar a todos los Estados de Europa en vastos talleres y, de hecho, por doquier se piensa más en el consumo y la producción que en la felicidad”2 . Y también cita a Benjamín Constant, en cuya opinión la actividad económica, a diferencia de la Antigüedad clásica, donde "el comercio era un accidente afortunado; hoy es el estado habitual, el único fin, la tendencia universal, la auténtica vida de las naciones. Éstas quieren la tranquilidad, y con la tranquilidad el bienestar, y, como fuente del bienestar, la industria"3.

Como consecuencia de la tendencia histórica recién descrita, la mayoría de las personas centran hoy más su actividad en lo que les acarrea provecho económico que en labores políticas. Después de la Segunda Guerra Mundial, esta tendencia se ha concretado en un modelo político-social encaminado hacia la abundancia y la riqueza, que hace que el Estado actual pueda denominarse con justicia “Estado del bienestar”. Según Gallego, podría afirmarse que la coincidencia en el tiempo y en el espacio - Edimburgo,

${ }^{1}$ Cfr. Elio A. Gallego García (2005: 159-203).

2 "La Cuestión del Veto Real” (en Escritos y Discursos de la Revolución, Madrid, 1990: 117), citado por Elio A. Gallego García (2005: 164).

${ }^{3}$ B. Constant: "De la Libertad de los Modernos Comparada con la de los Antiguos” (en Escritos Políticos, Madrid, 1989: 264), citado por Elio A. Gallego García (2005: 184). 
1776 - de la publicación de La Riqueza de las Naciones, de Adam Smith, con la patente de la máquina de vapor por parte de Watt, no sea enteramente fruto de la casualidad. Adam Smith habría considerado que la motivación principal para todo hombre era la de mejorar su condición, lo cual podría alcanzarse por un aumento de fortuna. En consecuencia el interés propio debía considerarse no como una pasión viciosa con beneficios públicos, como había sido concebida por Mandeville, sino como una inclinación natural no reñida con la virtud ${ }^{4}$.

Estamos de acuerdo con la caracterización que hace Gallego del Estado actual como un "Estado del bienestar", y con el hecho, también característico de nuestros días, de que los individuos, en general, centran más su trabajo y su tiempo en la obtención de ventajas económicas que en la participación en actividades políticas; pero no nos parece justo acusar al pensamiento de Adam Smith de ser la causa principal de estos fenómenos sociales. El economicismo actual es producto de teorías económicas positivistas, carentes de bases morales y muy ajenas a los ideales de nuestro autor, aunque pretendan fundamentarse en una de sus obras principales, $L a$ Riqueza de las Naciones $(R N)$.

Aunque Adam Smith consideraba que su teoría de la moral, de la ley y de la política económica eran científicas; estimaba que eran filosofía, porque él no ponía en compartimentos separados a la filosofía y a la ciencia. Usaba los términos “ciencia”, "filosofía” y "sistema” como conceptos intercambiables. Ciencia social significaba para Smith un sistema fundamentado en la ética, una elaboración sistemática que explica los hechos sociales desde la perspectiva de la vida moral del hombre. No era por tanto un sistema científico en el sentido positivista del término. En comparación con este último, la ciencia smithiana era profunda y aguda, no demostrable o deductiva. Aunque se basaba en la experiencia, su sistema era prescriptivo y deísta, porque se refería en último término a la Naturaleza divina y a la deidad intramundana de los estoicos, aunque no al Dios trascendente de los griegos y cristianos ${ }^{5}$.

Smith no habría estado de acuerdo con el giro epistemológico que se dio a la ciencia económica en el siglo XIX, la cual pretende tenerlo a él como padre. Si hubiera estado vivo habría lamentado la evolución de la economía hacia una ciencia altamente deductiva — la teoría del equilibrio general-, que se basa en axiomas no evidentes en vez de hacerlo en principios familiares a todos los hombres, y que termina produciendo un divorcio entre economía y ética, considerando a los individuos como meros átomos en las

\footnotetext{
${ }^{4}$ Cfr. Gallego (2005: 184-185).

${ }^{5}$ Cfr. Athol Fitzgibbons (1995: 92-94).
} 
negociaciones del mercado, ignorando la complejidad interior de los hombres, de cuyas acciones depende un mundo abierto y cambiante, no mecánico ${ }^{6}$. Adam Smith piensa que la prosperidad depende más de ciertas "virtudes individuales" que del modelo matemático al que se pretende hoy ajustarla $^{7}$. Esas virtudes individuales no son de origen platónico o aristotélico, es decir no tienden a la perfección del hombre, sino que son virtudes de corte ilustrado, como la prudencia interesada y la justicia meramente conmutativa, que permitirían a todos los hombres vivir en paz y prosperidad aunque cada uno busque principalmente su propio provecho.

Adam Smith pertenece a la Ilustración escocesa y su filosofía, aunque empirista y falta de metafísica, tiene todavía los rasgos fundamentales de una tradición en que la ética y la economía se compenetran estrechamen-

${ }^{6}$ Cfr. Leonidas Montes (2004: 162-164).

${ }^{7}$ Las ciencias económicas actuales han entendido la política económica smithiana en La Riqueza de las Naciones ( $R N$ ) como una ciencia positivista, al menos desde sus principales corrientes de pensamiento. Un estudio acabado de esta equivocación ha sido desarrollado por Leonidas Montes, en el libro citado en la nota anterior. En un capítulo sobre el origen newtoniano de la metodología de Smith, Montes desarrolla la tesis de que la ciencia económica neoclásica y otras ciencias económicas principales contemporáneas han malinterpretado la influencia de Newton en Smith porque han sobrevalorado sólo un aspecto, y quizá el menos importante, del método newtoniano, rasgo que ha sido considerado como la inspiración metodológica de La Riqueza de las Naciones (Cfr. Montes, 2004: 130-164).

Al comienzo del Libro III de los Principia, Newton desarrolla sus Regulae Philosophandi, exponiendo cuatro reglas para el estudio de la filosofía natural. Las cuatro acentúan fuertemente el rol de la inducción, por medio de la cual se revelan las causas de los fenómenos naturales, que es un momento del filosofar más creativo y difícil. Sin embargo, el paso posterior al descubrimiento de las causas, que es la aplicación de esos principios a todos los fenómenos, y consiste en la síntesis o composición, se ha privilegiado en las ciencias positivistas modernas, conduciendo a una interpretación axiomático-deductiva de la metodología de los Principia. Este fenómeno tiene su origen, según Montes, en la Ilustración francesa. El éxito de los Principia al crear un sistema matemático de la naturaleza ha determinado una interpretación particular de su método, universalizando la síntesis como el método científico por excelencia. Pero Newton dice en Opticks que la explicación de los fenómenos es mucho más sólida que su matematización (Cfr. Montes, 2004: 137-138). Newton creía en la verdad, y descubrió parte de ella con éxito. Sin embargo sabía que había mucho más en el trasfondo de lo revelado actualmente (Cfr. ibíd.: 140)

La ciencia económica positivista posterior a Adam Smith, tergiversando en ese sentido el método newtoniano, ha puesto el énfasis en las mediciones matemáticas, presuponiendo un comportamiento atomístico de los individuos en un sistema cerrado. Ignora el hecho fundamental de que los individuos están estructurados internamente, siendo inherentemente complejos y actuando en un mundo abierto y cambiante. Su fe en reducir las complejidades del comportamiento económico a un modelo matemático, inspirado en el mecanicismo, es inconsistente con el amplio proyecto de Smith (Cfr. Montes, 2004: 162-163) 
te $^{8}$. Es verdad que el tema de La Riqueza de las Naciones es la prosperidad económica de los individuos, a partir del ejercicio del interés por sí mismo, lo cual redunda en un crecimiento de la riqueza del país. Pero encontramos también en la misma obra referencias al ejercicio de la benevolencia, como conducta moral distinta pero compatible con el interés por sí mismo.

Por una parte, Adam Smith habría lamentado la interpretación que hace la economía clásica, positivista, de la eficiencia económica como un valor absoluto, y del interés individual que motiva la actividad económica como algo no moral ${ }^{9}$. Desde la filosofía smithiana que recorre La Riqueza de las Naciones, y que tiene como fundamento La Teoría de los Sentimientos Morales $^{10}$, el interés propio es un amor a sí mismo ${ }^{11}$, que puede ser moderado por medio de la simpatía y el espectador imparcial, permitiendo al individuo una actividad económica que acreciente el propio capital, sin competir injustamente con los demás y teniendo como fin el ahorro y la inversión, lo que redunda en el aumento de las oportunidades de trabajo para muchos.

${ }^{8}$ Cfr. Jeffrey Young (1997: 3-8).
${ }^{9}$ Cfr. Athol Fitzgibbons (1995: 190).
${ }^{10}$ Nos fundamentamos en el descubrimiento de una coherencia entre La Teoría de los Sentimientos Morales (TSM) y La Riqueza de las Naciones (RN). Algunos economistas alemanes del siglo XVIII — Hildebrand, Knies y principalmente Skarzynskiafirmaron que tal coherencia no existe, argumentando que el pensamiento de Adam Smith habría evolucionado desde una filosofía que hacía de la simpatía la base del comportamiento social, en La Teoría de los Sentimientos Morales, hacia una teoría que hace del egoísmo el motivo principal de esa conducta en La Riqueza de las Naciones, debido a la influencia que recibió de los materialistas franceses en el viaje que hizo a París justamente en el período que medió entre la composición de ambas obras (véase la introducción de D. D. Raphael y A. L. Macfie a la edición de TSM de Liberty Classics, Indianápolis, 1982, 20 ss). Esta supuesta incoherencia entre las dos obras principales de Adam Smith ha sido denominada Das Adam Smith Problem, y ha sido el origen de una larga discusión que dura hasta nuestros días, dentro de la cual encontramos argumentos importantes que la descalifican (Cfr. Leonidas Montes, 2004: 15-56).

Hemos argumentado en otro escrito que la solución a esa aparente dicotomía está en distinguir entre "amor a sí mismo prudente” y "egoísmo” en TSM, descubriendo así que el primero se encuentra en el origen del capitalismo justo propuesto en $R N$. El amor a sí mismo egoísta es moderado, según Smith, de acuerdo a un proceso racional realizado por el espectador imparcial, que tiene su origen en la simpatía (Cfr. María Elton, 2005: 69-125).

${ }^{11}$ Hemos traducido self-love por amor a sí mismo (cfr. voz self-love, Oxford Spanish Dictionary, Oxford University Press, 2003), para diferenciarlo del egoísmo —selfishness - , que nos parece es un principio moral perverso, mientras que el primero es virtuoso, aunque propio de una prudencia inferior, es decir de una virtud interesada (Cfr. Knud Haakonssen, 2002: X; María Elton, 2005: 78-101). En Spanish Dictionary, Simon \& Schuster's Internacional, Second Edition, MacMillan, USA, 1997, la traducción tanto de self-love como de selfishness es egoísmo, lo cual es contrario, nos parece, a la filosofía moral de Adam Smith. 
El ejercicio del amor a sí mismo moderado es la prudencia inferior, catalogada por Adam Smith entre las virtudes ${ }^{12}$, la cual orienta la actividad económica del individuo - motivada por el "deseo de mejorar la propia condición”, según La Riqueza de las Naciones ${ }^{13}$ — hacia el aumento de su capital para luego invertirlo, creando así ocasiones de trabajo para muchos operarios. Esta virtud no es, sin embargo, lo que frecuentemente llamamos prudencia ${ }^{14}$, la cual, en términos smithianos, es la máxima perfección de todas las virtudes intelectuales y morales, cercana al carácter del sabio académico o peripatético y propia de un gran general, un gran estadista o un gran legislador. Es más bien una prudencia epicúrea, que se dirige al cuidado de la propia salud, fortuna, rango y reputación individuales y, aunque es respetable, merece sólo una fría estima, por lo que es denominada "prudencia inferior" por nuestro autor ${ }^{15}$. Es una virtud que permite al individuo ser interesado e imparcial a la vez, lo cual se explica desde el proceso de la simpatía y el espectador imparcial, que le hace ponerse en el caso de una tercera persona imaginaria capaz de juzgar rectamente las propias reacciones y acciones de manera que, al mismo tiempo que se busca el propio provecho dentro de ciertos límites, se evita dañar a los demás y, de modo natural, no intencionado, se favorece a otros dándoles oportunidades de trabajo $^{16}$.

${ }^{12}$ Cfr. TSM, VI.i.1-16, 212 ss.

${ }^{13}$ Cfr. RN, II.iii.28, 341; 31, 343; 36, 345; IV.v.b.43, 540; IV.ix.28, 674.

${ }^{14}$ En la doctrina clásica platónico-aristotélica, y en la filosofía medieval de Tomás de Aquino, la prudencia es el hábito que nos inclina a deliberar sobre lo bueno y lo malo para el hombre en cuanto hombre, es decir la virtud que nos conduce a la vida buena y feliz, no a un aspecto particular de la vida. En la época moderna, en cambio, ha predominado una concepción de la prudencia entendida como un saber hacer las cosas de modo que se consiga el bienestar, por vías "razonables". A este significado de prudencia corresponde el concepto de prudence anglo-sajón, que se identifica con la prudencia inferior de Adam Smith (cfr. voz "Prudencia” en José Ferrater Mora, Diccionario de Filosofía, 1994, Vol. 3: 2944-2945).

15 Cfr. TSM, VI.i.15, 216.

${ }^{16}$ Para una explicación mucho más pormenorizada de ese proceso psicológicomoral individual y su influencia en el desarrollo de un capitalismo ético, cfr. María Elton (2005: 69-125). Ese capitalismo, basado en el ejercicio individual de la prudencia inferior, es el sistema económico propuesto por Adam Smith, al que dedica La Riqueza de las Naciones, por lo que tendría razón Raquel Lázaro al considerar que: “Smith dibuja una filosofía moral que describe el comportamiento general de la mayor parte de los hombres, no de una minoría, como podría ser la aristocracia, en sentido clásico. El filósofo escocés no apunta a la excelencia moral que alcanzan unos pocos —los héroes, verdaderos amantes de la virtud-, sino a la corrección moral que se puede reconocer en la mayoría” (cfr. Lázaro, 2003: 624). 
La prudencia inferior lleva consigo la práctica de las virtudes de la sobriedad y la laboriosidad, también por motivos interesados ${ }^{17}$, que redundan, según La Riqueza de las Naciones, en la formación de un tipo moral de hombre capaz de promover trabajo productivo entre muchas personas, opuesto al hombre derrochador del siglo XVIII, que daba trabajos serviles que terminaban sólo en consumición. Smith es un crítico del consumismo en esta obra. El hombre frugal es prudente y, aunque sólo busca su propio interés, de una manera no intencionada tiende a mejorar la condición de un gran número de trabajadores que dependen de su acumulación de capitales que siempre invierte en el mantenimiento de manos productivas, también por motivos interesados, promoviendo así a la vez el desarrollo de la virtud de la laboriosidad. El derrochador, en cambio, no estimula la experiencia de esa virtud, y empobrece a su país ${ }^{18}$.

Por otra parte, aunque el comportamiento interesado —siempre que sea prudente y justo- juega un papel principal en el desarrollo del capitalismo en La Riqueza de las Naciones, Adam Smith introduce, en esta misma obra, a la benevolencia de los hombres como un motivo moral cuyo ejercicio es necesario para corregir ciertos desequilibrios sociales que se producen en el desarrollo de la sociedad comercial libre. No basta el ejercicio individual de la prudencia inferior para que reine enteramente la justicia en la sociedad. La vulgarización del pensamiento de Smith, basada en su famosa aserción de que "no es de la benevolencia del carnicero, el cervecero o el panadero, que nosotros esperamos nuestra comida, sino de su consideración de su propio interés”, y que nosotros no nos dirigimos a la benevolencia de ellos, "sino a su amor a sí mismo, y nunca le hablamos de nuestras propias necesidades, sino de sus propias ventajas" ${ }^{\prime 19}$, puede llevar a establecer una contraposición irreductible entre amor a sí mismo y benevolencia

${ }^{17}$ Cfr. TSM, VI.i.11, 215. La detallada descripción de todos los rasgos de la prudencia inferior fue agregada por Smith a esta obra en su sexta edición, después de haber escrito La Riqueza de las Naciones (cfr. ibíd., VI. i.1, 212).

${ }^{18}$ Cfr. Adam Smith, RN, II.iii.1-42, 330-349. Es necesario hacer notar que Adam Smith no tiene la misma opinión recién expuesta en La Teoría de los Sentimientos Morales, IV.i, como bien ha señalado Samuel Fleischacker (Fleischacker, 2004: 109110). Smith afirma allí que los gastos en todo tipo de artículos de lujo es algo crucial para el desarrollo de la agricultura y de las ciudades, manteniendo a un gran número de pobres que sólo realizan trabajos serviles (cfr. TSM, IV.i.9, 183-184). Hemos visto, sin embargo, que en La Riqueza de las Naciones son las virtudes de la frugalidad y la laboriosidad las que producen riqueza y hacen grande a un país, lo que explica, seguramente, la introducción detallada de los rasgos de carácter del hombre que posee la prudencia inferior en la sexta edición de La Teoría de los Sentimientos Morales.

${ }^{19} R N$, I.ii.2, 26-27. 
en su obra, desconociendo por una parte la moderación racional que lleva consigo el primero y, por otra, los ámbitos donde se debe ejercer la segunda en la sociedad civilizada. Esto último matiza en cierta medida la interpretación que señalábamos al comienzo de esta introducción, según la cual el legado de Adam Smith consistiría sólo en fomentar el comercio y el bienestar, sin interesarse de ninguna manera por alguna participación política de los individuos en la sociedad.

Nos proponemos, pues, argumentar en las próximas secciones de este artículo a favor de una interpretación más amplia de las fuerzas morales que se intercalan en la sociedad comercial propuesta en La Riqueza de las Naciones. Nuestra tesis es que aunque este libro se centre fundamentalmente en una política económica dentro de la cual la prudencia inferior e interesada tiene un rol fundamental, no deja completamente de lado la necesidad de imponer, por parte de la autoridad, ciertos comportamientos benevolentes al interior de esa misma política.

En el Libro V de La Riqueza de las Naciones, Adam Smith establece una serie de deberes del gobernante: la defensa militar del país, la administración de justicia y la provisión de la necesaria educación a los trabajadores de escasos recursos. Especialmente los dos últimos tienen que ver con el crecimiento de la sociedad comercial, ya que no puede haber fair play - juego limpio - en el mercado si no se ejercita la justicia conmutativa entre sus actores, la cual debe ser salvaguardada por la autoridad gubernamental; por otra parte, si el gobernante no promueve la educación de la gente común, ésta llegará a constituir una amenaza contra la estabilidad de la sociedad y la autoridad del gobierno, debido a su ignorancia, su apatía y su inconciencia. Pero también este último tiene que ver con el primero, porque los que carecen de educación moral no tendrán el espíritu heroico necesario para la defensa de la patria.

Nuestra investigación ha versado sobre el tercero de estos deberes. El orden de nuestra exposición seguirá los siguientes pasos: en la sección 2 explicaremos por qué la benevolencia puede ser exigible en una sociedad libre de corte smithiano; en la sección 3 nos referiremos a las deformaciones de carácter y de entendimiento que lleva consigo la división del trabajo, a pesar de ser una inclinación de la naturaleza humana que está en la base del desarrollo de la sociedad comercial, mostrando a la vez cómo el gobernante debe imponer al público la obligación de proveer los medios pata educar a los más pobres; y en la sección 4 haremos una recapitulación de lo expuesto, contrastando nuestra tesis con algunas opiniones contrarias. 


\section{2. ¿Puede exigirse la benevolencia en la sociedad?}

En La Teoría de los Sentimientos Morales, Adam Smith hace una comparación entre la justicia y la beneficencia (o benevolencia) ${ }^{20}$. Las acciones benevolentes merecen recompensa y son causa de la gratitud simpatética del espectador. Las acciones dañinas, en cambio, merecen castigo, porque suscitan el resentimiento del que recibe el daño y del espectador. Las acciones benevolentes son libres, no pueden ser impuestas bajo castigo, porque su falta no hace ningún mal positivo. El resentimiento es un sentimiento dado por la naturaleza al hombre con el fin de que se defienda de todo daño o injusticia, no de la falta de benevolencia. La justicia es, en consecuencia, obligatoria bajo castigo. Por eso Smith afirma en La Riqueza de las Naciones que uno de los deberes del soberano, de acuerdo al sistema de la libertad natural, es proteger a todo miembro de la sociedad de la opresión de otro miembro, estableciendo una administración de justicia ${ }^{21}$.

Los sentimientos benevolentes se extienden, según Adam Smith, por naturaleza, a los hijos, a los padres, a los parientes, a los amigos, a los benefactores, es decir a todos aquellos a los que más se ama y venera de modo natural. Ahora bien, como la felicidad propia y de todos los cercanos recién mencionados depende del Estado en que se ha nacido y se ha sido educado, la benevolencia se abre también hacia la nación, que también le ha sido encomendada al hombre por naturaleza, hasta tal punto que sacrificarse por la propia patria es conveniente, aunque difícil, y pocas personas pueden hacerlo ${ }^{22}$. No existen, por tanto, en el hombre sentimientos benevolentes que por naturaleza se extiendan hacia los extraños.

En la sociedad comercial el hombre necesita de la cooperación y asistencia de grandes multitudes, de las cuales en general no puede esperar benevolencia, porque a lo largo de toda su vida consigue hacer nada más que unas pocas amistades. Por eso el hombre, que a diferencia del animal "tiene constantemente necesidad de la ayuda de sus hermanos, sería vano que la esperara sólo ${ }^{23}$ de su benevolencia. Es probable que tenga más éxito en obtenerla si apela al amor a sí mismo en su propio provecho, y les muestre que es por su propia ventaja que le hagan lo que les está pidiendo [...] No es de la benevolencia del carnicero, el cervecero o el panadero, que nosotros esperamos nuestra comida, sino de la consideración de su propio

${ }^{20}$ Cfr. TSM, II.ii.1-10, 78-82. La beneficencia y la benevolencia son términos intercambiables en Adam Smith (cfr. Gloria Vivenza, 2001: 66-67 y 198).

${ }^{21}$ Cfr. RN, IV.ix.51, 688.

${ }^{22}$ Cfr. TSM, VI.ii.2, 227-228.

${ }^{23} \mathrm{Cfr}$. $R N$, I.ii.2, 26. Las cursivas son mías. 
interés. Nosotros nos dirigimos no a su humanidad [benevolencia], sino a su amor a sí mismo, y nunca le hablamos de nuestras propias necesidades, sino de sus propias ventajas"24.

Los términos señalados en cursivas han servido a Fleischacker para hacer una exégesis del famoso texto smithiano. Efectivamente la benevolencia cumple un rol muy pequeño en los intercambios económicos, que no es lo mismo que no cumpla ninguno. La benevolencia es económicamente poco importante, porque la ayuda que el hombre necesita de sus semejantes para asegurarse los necesarios bienes materiales es una cooperación de las grandes multitudes. La red por medio de la cual los seres humanos producen e intercambian los diversos bienes materiales se extiende sobre una amplia sociedad, a veces sobre toda la raza humana. Es imposible incluso conocer bien a todos los miembros de una pequeña ciudad como para que haya "benevolencia particular" entre ellos. Si nuestros intercambios económicos estuvieran enraizados en la benevolencia, tendría que existir una "benevolencia general” entre individuos anónimos, y la benevolencia es un sentimiento muy débil ${ }^{25}$. Por eso Smith afirma en el texto citado en el párrafo anterior que no se puede esperar ayuda económica de los demás sólo de su benevolencia, porque no hacemos intercambios económicos por "espíritu público"26 ni por "benevolencia universal”27.

La benevolencia parece ejercerse, pues, de una manera meramente privada, y no es exigible en las relaciones comerciales, las cuales, a su vez, deben regirse por las leyes de la justicia conmutativa, dentro de la cual no cabe la benevolencia. Sólo a la justicia conmutativa se la puede llamar propiamente justicia, según Adam Smith ${ }^{28}$. En sus clases de jurisprudencia enseñó que los derechos que pueden ser exigidos son los derechos perfectos, que son garantizados por la justicia conmutativa. Los derechos imperfectos pertenecen a la justicia distributiva, y no caen bajo la jurisdicción de la ley, sino que pertenecen solamente a la moral. Por ejemplo, es virtuoso ayudar al pobre, pero no es obligatorio jurídicamente ${ }^{29}$.

Recordemos que para Adam Smith sólo la justicia es exigible bajo castigo. A su vez concibe la justicia como una virtud negativa, es decir como aquella que impide el daño provocado por los otros, según lo explicado en La Teoría de los Sentimientos Morales ${ }^{30}$. De acuerdo con este con-

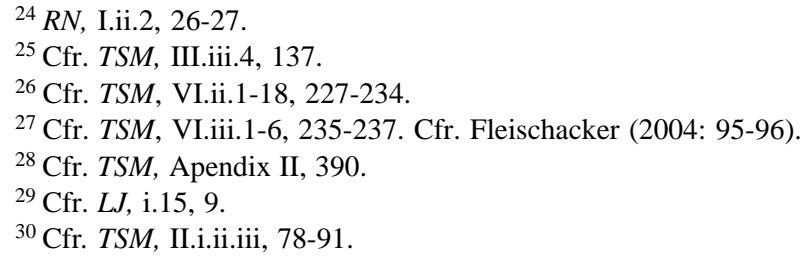


cepto de justicia, el principal propósito del gobernante civil, afirma en sus clases de jurisprudencia, es preservarla entre los miembros del Estado e impedir que los individuos se dañen unos a otros dentro de la misma sociedad. Se trata de una mera justicia conmutativa, que es violada cuando alguien le hace mal al otro sin una causa justificada ${ }^{31}$. "El comercio y las manufacturas pueden raramente florecer en un estado que no goza de una administración regular de justicia, en el cual la gente no se sienta segura en la posesión de sus propiedades, en el cual la confianza en los contratos no esté apoyada por la ley, y en el cual la autoridad del estado no se suponga que está regularmente empleada en exigir el pago de las deudas por todos aquellos capaces de pagar. En definitiva, el comercio y las manufacturas pocas veces pueden florecer en un estado donde no hay cierto grado de confianza en la justicia del gobierno"32. El gobierno tiene el deber de proteger tanto como pueda a cada miembro de la sociedad de la injusticia u opresión de otro miembro de ella, mediante el establecimiento de una administración de justicia ${ }^{33}$.

Es sintomática la afirmación que hace Adam Smith en La Teoría de los Sentimientos Morales, según la cual sólo la justicia es el pilar de la sociedad, mientras que la beneficencia o benevolencia es sólo su embellecimiento opcional. A pesar de que la naturaleza "exhorta a los hombres a realizar actos de beneficencia”, dice Smith, “por la grata conciencia de recibir una merecida recompensa, ella [la naturaleza] no ha considerado necesario proteger y exigir esa práctica mediante el terror de un merecido castigo en caso de que sea descuidada. Ella es el ornamento que embellece, no el edificio, no la base que lo sostiene y por ello bastaba con recomendarlo y no era en absoluto indispensable imponerlo. La justicia, en cambio, es el principal pilar que sostiene todo el edificio. Si ella es removida, entonces, la grandiosa e inmensa estructura de la sociedad humana, esa red cuya construcción y sostenimiento parece haber sido en este mundo, por así decirlo, la preocupación peculiar y querida de la Naturaleza, se desmenuzaría en átomos"34.

En opinión de Vivenza, Adam Smith es un representante del pensamiento del siglo XVIII, para el cual era una incongruencia incluir la justicia conmutativa y la justicia distributiva como especies del género justicia, ya que ambos conceptos son opuestos, porque el segundo supone una desigualdad entre los hombres, mientras que el primero no. Los clásicos no

\footnotetext{
${ }^{31}$ Cfr. $L J$, i.9, 7.

${ }^{32} R N$, V.iii.7, 910.

${ }^{33}$ Cfr. TSM, II.ii.6, 87-88.

${ }^{34}$ TSM, II.ii.3.4, 86.
} 
tuvieron dificultad en aceptar que los hombres no son iguales. De allí la importancia de la beneficencia como forma de justicia entre ellos. El cristianismo considera iguales a todos los hombres, pero justifica cierta desigualdad porque unos tienen autoridad sobre otros, como el soberano del Estado, la aristocracia y el padre de familia. Es conveniente y justo que el que tiene autoridad haga el bien a los otros. Dentro de este último marco social se puede introducir la justicia distributiva ${ }^{35}$.

Según Young, la opinión aristotélico-escolástica es que la distribución es un asunto de justicia, y no sólo de moral personal. Es objeto, por tanto, de exigencia política por parte del gobierno ${ }^{36}$. Adam Smith considera, en cambio, que la justicia distributiva es equivalente a la benevolencia, la cual constituye un deber de caridad o generosidad en las ocasiones pertinentes ${ }^{37}$. La opinión smithiana está de acuerdo con la tradición protestante de la ley natural, y sirve para quitar responsabilidades de equidad distributiva al gobierno, las cuales no serían cuestiones de justicia propiamente tal ${ }^{38}$.

Sin embargo, es posible sostener que, según Adam Smith, una cierta benevolencia hacia los necesitados, con vistas a mantener la igualdad social necesaria para el desarrollo de la libertad natural, aunque no puede ser exigida por la fuerza de la ley por parte de los individuos, puede, sin embargo, ser impuesta, bajo pena de castigo, por parte del legislador, con relación a ciertos servicios públicos.

"De acuerdo al sistema de la libertad natural", dice Smith, "el soberano tiene sólo tres deberes que atender; tres deberes de gran importancia, sin duda, pero simples e inteligibles para el entendimiento común; primero, el deber de proteger la sociedad de la violencia e invasión de otras sociedades independientes; segundo, el deber de proteger, tanto como sea posible, a todo miembro de la sociedad de la injusticia u opresión de todo otro miembro de ella, o el deber de establecer una exacta administración de justicia; y, tercero, el deber de erigir y mantener ciertas obras públicas y ciertas instituciones públicas, que nunca serían erigidas y mantenidas por el interés de algún individuo o grupo de individuos; porque sus ganancias no podrían nunca reembolsar el gasto a un individuo o pequeño grupo de individuos, a pesar de que podría frecuentemente hacer más que reembolsarlo para la sociedad en general”39.

${ }^{35}$ Cfr. Gloria Vivenza (2001: 198-200).

${ }^{36}$ Cfr. Jeffrey Young (1997: 131). Para hacer esta afirmación cita a Odd Langholm, Economics in the Medieval Schools: Wealth, Exchange, Value, Money and Usury According to the Paris Theological Tradition 1200-1350, Leiden: E. J. Brill, 1992.

${ }^{37}$ Cfr. TSM, VII.ii.10, 269-270; Apendix II, 389-390, 392 у 392-393.

${ }^{38}$ Cfr. Jffrey Young (1997: 130).

${ }^{39} R N$, IV.ix.51, 687-688. 
El tercero de esos deberes es ciertamente un asunto de justicia distributiva, equivalente a la benevolencia, dentro de la tradición protestante de la ley natural a la que pertenece Smith ${ }^{40}$. Recordemos que la benevolencia no puede ser exigida por la jurisprudencia, la cual se refiere siempre sólo a la justicia conmutativa en el contexto de la tradición iusnaturalista protestante. La benevolencia sólo satisface derechos imperfectos. Sin embargo existe en la obra de Adam Smith un cierto interés por la equidad distributiva, que aparece en textos cortos repartidos de manera asistemática ${ }^{41}$.

Vimos en La Teoría de los Sentimientos Morales que Adam Smith hace una comparación entre las virtudes de la justicia y la benevolencia, afirmando que esta última no puede ser exigida por la fuerza como la justicia, porque su falta no tiende a ningún mal positivo, por lo cual no expone a ningún castigo, aunque de ella se sigan bienes que razonablemente se espe$\operatorname{ran}^{42}$. La justicia conmutativa en cambio puede ser ordenada por la fuerza, porque los individuos, que son iguales naturalmente y con anterioridad a la institución del gobierno civil, tienen el derecho a defenderse de las injurias, y a exigir castigo por las que se le han hecho, cosa que es aprobada por el espectador generoso ${ }^{43}$.

Sin embargo, Smith indica en ese contexto que el grado más común de bondad o beneficencia, aunque no puede ser impuesto por la fuerza entre iguales ${ }^{44}$, es decir no puede ser exigido entre los individuos como la justicia conmutativa, puede ser impuesto por la autoridad. "Un superior puede, ciertamente, con la aprobación universal, obligar a aquellos que están bajo su jurisdicción a comportarse, en ese respecto (benevolentemente), con una cierta corrección unos con otros. Las leyes de las naciones civilizadas obligan a los padres a mantener a sus hijos, a los hijos a mantener a sus padres, e imponen sobre los hombres muchos otros deberes de beneficen-

${ }^{40}$ Cfr. Jeffrey Young (1997: 130). Desde esta identificación, que Gloria Vivenza considera aceptable, Young puede explicar, refiriéndose a una serie de observaciones que hace Smith, que este último piensa que la benevolencia o "ciertos buenos oficios" pueden ser impuestos por el Estado (cfr. Gloria Vivenza, 2001: 200). Nosotros estamos de acuerdo con esta interpretación, y argumentaremos en qué sentido esa imposición de la benevolencia acrecienta la libertad de la sociedad, aunque no suplanta ni iguala a la justicia conmutativa como fundamento esencial de la sociedad.

${ }^{41}$ Cfr. Jeffrey Young (1997: 130-132).

${ }^{42}$ Cfr. TSM, II.ii.1.3, 78.

${ }^{43}$ Cfr. TSM, II.ii.1.7, 80-81.

${ }^{44}$ Cfr. TSM, II.ii.1.7, 80. Nótese que Smith habla en este caso de deberes de beneficencia, que es una actitud moral, es decir que la autoridad obliga a practicar la benevolencia en ciertas materias indispensables para el funcionamiento libre de la sociedad. 
$\mathrm{cia}^{45}$. Al magistrado civil se le ha confiado el poder no sólo de preservar la paz pública reprimiendo la injusticia, sino promoviendo la prosperidad de la comunidad, estableciendo una buena disciplina, y oponiéndose a toda suerte de vicios e incorrecciones; en consecuencia, él puede prescribir reglas que no sólo prohíban las mutuas injurias entre los ciudadanos, sino que también impongan buenos servicios en un cierto grado"46.

Según J. Young, que es, de acuerdo con G. Vivenza, el autor más autorizado en la cuestión de la identificación de la justicia distributiva con la benevolencia en Adam Smith ${ }^{47}$, el concepto de justicia distributiva aristotélico-escolástico, según el cual esa virtud es una obligación de la comunidad o del gobernante como representante de la comunidad ${ }^{48}$, y el concepto protestante según el cual la justicia distributiva es sólo caridad, son conciliados consistentemente en el texto de Smith citado en el párrafo anterior ${ }^{49}$. Como dijimos anteriormente, en Lectures on Jurisprudence (A), i.16), que recoge parte de las clases de Filosofía Moral que daba Adam Smith en la Universidad de Glasgow, en el contexto de la tradición jurídica protestante hace una diferencia entre derechos perfectos y derechos imperfectos. Estos últimos no son objeto de justicia propiamente. Así, una persona puede tener un derecho perfecto a recibir los frutos de su trabajo, pero un mendigo sólo tiene un derecho imperfecto a recibir subsistencia. El legislador debe proteger los derechos perfectos, pero no los imperfectos, que quedan así fuera de la esfera de su acción. Esta manera de pensar contrasta fuertemente con el concepto aristotélico-escolástico de justicia distributiva, según el cual la distribución es un asunto de justicia, y no sólo de moral personal, y es objeto de la política pública. La mayor parte de la literatura secundaria sobre Adam Smith parece tomar como decisiva, en La Teoría de los Sentimientos Morales, la definición de justicia como mera justicia conmutativa. Así, para muchos economistas es sorprendente que Smith no considere la responsabilidad que tiene el legislador respecto de los pobres. Sin embargo Istvan Hont y Michael Ignatieff han argumentado recientemente que, aunque Smith se inserte en esa tradición de pensamiento iusnaturalista protestante, pensaba que un sistema de libertad natural tiene que asegurar un mínimo de justicia distributiva, elevando el nivel de vida de las clases ba$\mathrm{jas}^{50}$. Esa literatura secundaria no ha intentado unir los textos smithianos

${ }^{45}$ Las cursivas son mías, para hacer notar que el magistrado obliga, en esos casos, a practicar un deber moral, que debería tener su origen en los sentimientos naturales del hombre, cuya conducta sin embargo puede ser defectuosa.

${ }^{46}$ TSM, II.ii.1.8, 81.

${ }^{47}$ Cfr. Gloria Vivenza (2001: 199-200).

${ }^{48}$ Cfr. Josef Pieper (1980: 143-145).

${ }^{49}$ Cfr. Jeffrey Young (1997: 133).

${ }^{50}$ Cfr. Istvan Hont y Michael Ignatieff (1983: 113). 
breves, pero importantes, acerca de la justicia distributiva —o benevolencia exigida por el legislador- de una manera sistemática ${ }^{51}$.

Aunque la beneficencia no es exigible entre iguales, como la justicia conmutativa, el soberano puede, con la aprobación de la comunidad, establecer algunas leyes que requieran actos de benevolencia por parte de la sociedad, en función del bien común. Es una orden que viene de una autoridad, no de un igual. La beneficencia tiene una dimensión pública, y puede ser mandada por el gobernante incluso bajo pena de castigo ${ }^{52}$. Fleischacker atribuye esta tensión smithiana entre dos posiciones aparentemente opuestas: por un lado la libertad de la beneficencia y, por otro, su exigibilidad en algunos asuntos por el soberano, a la dificultad que encuentra Smith en establecer un criterio nítido sobre lo que es un "daño positivo y real", objeto de la justicia conmutativa. Desde esa supuesta indefinición, ser negligente en la mantención de los hijos puede considerarse como hacer un daño positivo y real a otro, y no dar una educación adecuada puede equivaler a dañar la libertad de otro ${ }^{53}$. Nos parece que esta interpretación tiende a descalificar la argumentación de Adam Smith, pero no puede hacer decir a Smith lo que no afirma. En un texto recién citado, Smith hace una clara diferencia entre "prohibir injurias mutuas" e imponer "buenos servicios en cierto grado" 54 . Lo primero es objeto de la justicia conmutativa, y lo segundo, de la justicia distributiva o benevolencia.

Estamos de acuerdo, por otra parte, con la afirmación de Fleischacker de que existe una tensión entre esas dos posiciones aparentemente opuestas. Pero esa tirantez afloja si consideramos algunas afirmaciones subsiguientes de Smith. "De todos los deberes del legislador”, dice, “éste [exigir algunos servicios públicos], quizá, es el que requiere una mayor delicadeza y reserva para ejecutarlo con corrección y juicio. Descuidarlo enteramente significa exponer a la comunidad a muchos grandes desórdenes y monstruosidades espantosas, y excederse es destructivo de toda libertad, seguridad y justicia (conmutativa)" 55 . Así vemos que el magistrado debe ser tan juicioso o virtuoso como para mandar sólo lo estrictamente necesario para que el sistema de la libertad natural siga su curso. La benevolencia es una responsabilidad moral privada porque, aunque su falta es una culpa moral, no es exigible legalmente ${ }^{56}$. Pero se convierte en una responsabilidad públi-

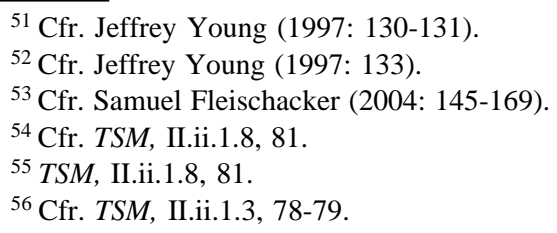


ca cuando el legislador, representando a la sociedad, exige al público actuar de acuerdo con este principio que se encuentra en su naturaleza. Al comienzo de La Teoría de los Sentimientos Morales, Smith dice que "por muy egoísta que se suponga es el hombre, hay evidentemente algunos principios en su naturaleza que lo hacen interesarse en la suerte de los otros, y convierten su felicidad en algo necesario para él, a pesar que no obtenga ningún beneficio de ella, sino sólo el placer de contemplarla"57. El legislador, si es virtuoso, impone la obligación de la benevolencia sólo en aquellas pocas instancias en que la justicia conmutativa, por sí misma, no puede corregir ciertas desigualdades surgidas al interior del sistema de la libertad natural. Pero la justicia conmutativa, que supone por lo demás una igualdad entre los individuos, sigue siendo el fundamento esencial que hace posible la vida social ${ }^{58}$.

\section{División del trabajo, benevolencia y educación}

En el Capítulo 1 del Libro I de La Riqueza de las Naciones, Adam Smith trata de la división del trabajo, considerando su importancia para la prosperidad económica de una nación. "La división del trabajo, en la medida en que puede ser introducida, ocasiona en todo arte un aumento proporcional de sus poderes productivos"59. "Es la enorme multiplicación de las distintas artes, que son consecuencia de la división del trabajo, la que ocasiona, en una sociedad bien gobernada, esa riqueza universal que se extiende a las categorías más bajas de la gente"60. Ahora bien, el desarrollo de la industria, consecuencia de la división del trabajo, contribuye también al perfeccionamiento moral de los individuos, haciéndolos, en concreto, diligentes, sobrios y prósperos ${ }^{61}$. "Nosotros somos más diligentes que nuestros antepasados”62, dice Smith. En cambio la concentración de las artes en un solo individuo, "el hábito de deambular y de una aplicación sin cuidado e indolente, que natural o más bien necesariamente adquiere todo trabajador rural obligado a cambiar de trabajo y herramientas cada media hora, y a emplear sus manos de veinte maneras diferentes casi todos los días de su vida, lo vuelve casi siempre holgazán y flojo, e incapaz de cualquier esfuerzo enérgico, ni siquiera en las ocasiones más apremiantes”63.

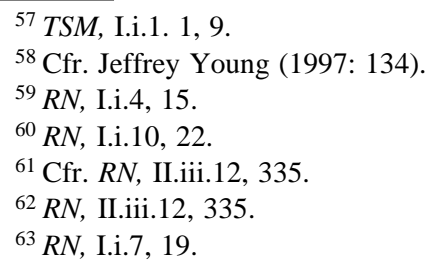


La división del trabajo lleva consigo, pues, prosperidad material y perfeccionamiento moral. Sin embargo tiene también como consecuencia ciertos efectos deshumanizadores en la gente común, descritos por Adam Smith en el Libro V de La Riqueza de las Naciones. "Con el progreso de la división del trabajo, la ocupación de gran parte de los que viven del trabajo, esto es, de la mayoría de la gente, se limita a unas pocas operaciones simples, frecuentemente una o dos. Mas el entendimiento de la mayoría de los hombres se forma necesariamente por su trabajo ordinario, por lo que el hombre que se dedica toda su vida a realizar unas pocas operaciones simples, de las cuales sus efectos son también, quizá, siempre los mismos, o casi los mismos, no tiene ocasión de ejercitar su entendimiento, o de inventar nuevos recursos para solucionar las dificultades nuevas. Él naturalmente pierde, en consecuencia, el hábito del ejercicio del entendimiento, y con frecuencia llega a ser tan estúpido e ignorante como es posible serlo a una criatura humana. La apatía de su mente lo vuelve no sólo incapaz de gozar o compartir una conversación racional, sino también de concebir o imaginar algún sentimiento generoso, noble o tierno, y consecuentemente de formar algún juicio justo respecto de los deberes ordinarios de la vida privada"64.

La desigualdad de inteligencia y carácter moral entre los hombres no proviene de la naturaleza, según afirma Smith en Lectures on Jurispruden$c e^{65}$, sino de los hábitos adquiridos en la propia ocupación ${ }^{66}$, y afecta de modo negativo a los que viven de trabajos especializados muy simples. Esta última consideración es retomada en La Riqueza de las Naciones, donde Smith dice que "la diferencia en los talentos naturales entre los hombres es, en realidad, mucho menos que la conciencia que tenemos de ella; y la diferencia de ingenios que parece distinguir a los hombres de distintas profesiones, cuando han llegado a la madurez, no es tanto la causa, en muchas ocasiones, como el efecto de la división del trabajo. La diferencia entre los caracteres más disímiles, entre un filósofo y un mozo de carga, por ejemplo, parece surgir no tanto de la naturaleza como del hábito, la costumbre y la educación. Cuando llegaron al mundo, y durante los primeros seis u ocho años de existencia, eran quizá muy semejantes, y ni sus padres ni sus compañeros de juego podían percibir diferencias notables entre ellos. Cerca de

${ }^{64} R N$, V.i.f.50, 781-782.

${ }^{65}$ Cfr. $L J$, vi.47, 348.

${ }^{66}$ Adam Smith adopta la teoría de la imaginación de David Hume en La Teoría de los Sentimientos Morales y en cualquier parte de su obra que tenga relación con esta primera (cfr. Knud Haakonssen, 2002: XII). Los hábitos intelectuales y morales dependen por tanto de la variedad de las percepciones -impresiones, ideas y distintos tipos de asociaciones entre éstas - que cada individuo haya tenido oportunidad de hacer de acuerdo a su ocupación ordinaria. 
esa edad, o pronto después de ella, se emplearon en diferentes ocupaciones. Entonces comenzó a notarse la diferencia de talentos, que fue agrandándose gradualmente, hasta que al fin la vanidad del filósofo no quiso reconocer ningún parecido. Sin embargo, sin la disposición al intercambio, cada hombre se habría procurado todo lo que quisiera como necesario y conveniente para su vida. Todos habrían tenido que realizar los mismos deberes, y el mismo trabajo, no habría habido esa diferencia de empleo ni ocasión para una gran diferencia de talentos"67.

En definitiva, contraponiendo algunos pasajes del Libro I con otros del Libro V de La Riqueza de las Naciones, nos encontramos con una aparente contradicción: la división del trabajo, como consecuencia del progreso de la sociedad, tiende, por una parte, a mejorar el rendimiento de la propia labor, haciéndola más productiva, y hace diligentes y sobrios, y por tanto virtuosos, a algunos trabajadores; mientras que, por otra parte, a los hombres más comunes los vuelve apáticos, ignorantes y estúpidos, debido a la rutinaria simpleza de su labor. En esta coyuntura cabe la exigencia por parte de los gobernantes de requerir conductas benevolentes de la sociedad, teniendo en vista el bien público. Adam Smith afirma que en toda sociedad civilizada los trabajadores indigentes caen en ese estado de apatía, ignorancia y estupidez, a no ser que el gobierno se empeñe en impedirlo 68 .

Cabe, pues, que el legislador establezca ciertas obligaciones para la sociedad, entre ellas que se haga cargo de la educación de la gente común. Esto es así a pesar de que Adam Smith aplica la libre competencia también al trabajo de la enseñanza. Considera que las instituciones educativas para los jóvenes - ya sean escuelas o universidades - deben ser sostenidas con los honorarios que pagan los estudiantes, según el sistema de la libertad natural. Como en otras profesiones, si los salarios de los que depende la subsistencia de los profesores están sujetos a competencia, los maestros se esforzarán en realizar mejor su tarea. Si esas remuneraciones, en cambio, son fijas porque las proporciona una fundación, y los alumnos no pueden elegir sus profesores, los educadores serán negligentes ${ }^{69}$. Dentro de esta política no cabe que el Estado se haga cargo de la educación. Sin embargo, el legislador debe intervenir cuando se trata de la educación de la gente común, que puede sufrir una gran apatía de la mente como consecuencia de la división del trabajo, ya que no gozan del tiempo ni de los privilegios necesarios para desarrollar sus talentos.

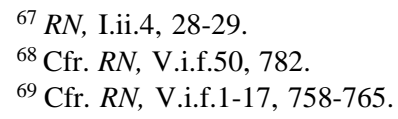


"La educación del pueblo requiere más de la atención del público en una sociedad civilizada y comercial, que la que requiere la gente de rango y fortuna"70, dice Smith. Los más pobres no serán nunca tan instruidos como los que pertenecen a una categoría social alta, pero "pueden adquirir en períodos tempranos de su vida las partes más esenciales de su educación, como leer, escribir y realizar operaciones aritméticas ${ }^{71}$, lapso de tiempo en que gran parte de ellos, incluso los que son criados para las ocupaciones más bajas, tienen tiempo de adquirirla, antes de ser empleados en el trabajo. Con un pequeño gasto el público puede facilitar, estimular e incluso imponer sobre casi toda la gente, la necesidad de adquirir lo más esencial de su educación"72.

Los textos del Libro V de La Riqueza de las Naciones que acabamos de citar pueden ser leídos a la luz de la argumentación de la sección anterior basada en el texto de La Teoría de los Sentimientos Morales, según la cual el magistrado civil puede imponer a la sociedad la realización de algunos buenos servicios para la prosperidad de toda la comunidad. Recordemos que esas referencias textuales, que conforman una unidad, tienen como idea principal que, aunque la benevolencia sea una conducta meramente caritativa, y no exigible en general bajo pena de castigo como la justicia conmutativa, es necesario que sea impuesta por la autoridad en ciertas ocasiones. Que la sociedad se haga cargo de la educación de la gente común es sin duda una de esas oportunidades.

"El público puede facilitar esa adquisición”, dice Smith, "estableciendo en cada condado o distrito una pequeña escuela, donde los niños puedan ser enseñados por una retribución tan moderada que, aun el trabajador más común pueda afrontarla; el maestro debe ser pagado en parte, no enteramente por el público; porque si lo es enteramente, o principalmente pagado por él, comenzará pronto a ser negligente en su negocio"73. Esta

${ }^{70} R N$, V.i.f.52, 784 .

${ }^{71}$ Tres veces en el Libro V, Adam Smith dice que las tres partes esenciales de la educación, a la que una vez menciona como "literary education", consisten en "learning to read, write, and account” (cfr. RN, V.i.f.16, 764; 42, 777; 54, 785). Hemos traducido account por realizar operaciones aritméticas, porque cuando habla de quienes se hacían cargo de esta parte de la educación en Grecia se refiere a este tercer aprendizaje perteneciente a lo esencial de la educación como "account according to the arithmetick of the times" (cfr. RN, V.i.f.42, 777).

${ }^{72} R N$, V.i.f.54, 785.

${ }^{73} R N$, V.i.f.55, 785. Adam Smith se refiere a esos deberes como obligaciones del público, no del Estado. En ningún momento señala que el público deba pagar impuestos para que el Estado se haga cargo de la educación de los más pobres, sino que siempre se refiere en términos generales al "público". Menciona experiencias históricas en Escocia e Inglaterra de ese tipo de educación, denominando a esas escuelas promovidas 
propuesta de Adam Smith se basa en la experiencia histórica de las "escuelas de caridad" en Escocia e Inglaterra, pertenecientes a un condado y promovidas por el público ${ }^{74}$. Nada dice Smith sobre la precisa forma de financiamiento de esas instituciones. Blaug afirma que, según el sistema escocés, el costo de los edificios de esos colegios en cada distrito rural era financiado por impuestos a los herederos y arrendatarios locales, mientras que en las ciudades era pagado con fondos municipales ${ }^{75}$.

Sin embargo, esta forma de financiamiento no implicaba que el legislador fuera el encargado, al mismo tiempo, de implementar un sistema estatal de educación pública. Más bien Smith se refiere a ciertas tareas del público, o de la sociedad, respecto a la enseñanza que se debía impartir en estas escuelas, señalando algunas modalidades para su eficacia, como la introducción de la geometría y la mecánica, y la supresión del latín en la educación literaria. También indica que el público debe otorgar premios o distinciones a los alumnos que destaquen en el aprendizaje ${ }^{76}$. Atendiendo a los principios generales de su sistema de libertad natural, Smith otorga al legislador la función sólo de subsidiar a la iniciativa privada para que ésta promueva esa educación personalmente ${ }^{77}$.

Así Adam Smith introduce la necesidad de instituciones educativas benéficas para la gente común, en la sociedad comercial, como un asunto de justicia distributiva, es decir de benevolencia. Cabe cuestionar si este ejercicio de la justicia distributiva por parte del público, propuesta en La Riqueza de las Naciones, es propiamente la benevolencia de que habla Smith en $\mathrm{La}$ Teoría de los Sentimientos Morales, o una mera corrección de un desequilibrio social para que funcione bien el sistema de la libertad natural. Nos parece que las dos cosas. Aunque Smith no use la palabra "benevolencia" en La Riqueza de las Naciones, sus explicaciones de lo que debe hacer el público en este caso - atención a la educación del pueblo, establecimiento de una escuela en cada condado, pago de impuestos para costear los salarios para los maestros que atenderán esas escuelas- constituyen conductas benevolentes, morales, de ayuda a los pobres. Por otra parte, la

por el público y pertenecientes a un condado como "escuelas de caridad". Para su eficacia, señala algunas modalidades de enseñanza que debería adoptar el público, como geometría, mecánica y una cierta medida de educación literaria, no de latín, que la gente común pueda aplicar después en su trabajo. Dice que el público puede dar premios o distinciones para aquellos niños que se distingan en ese aprendizaje. En ningún momento habla de programas del Estado (cfr. RN, V.i.f.55-56, 785-786).

${ }^{74}$ Cfr. $R N$, V.i.f.55, 785-786.

${ }^{75}$ Cfr. Mark Blaug (1975: 571-572).

${ }^{76}$ Cfr. $R N$, V.i.f.56, 786.

${ }^{77}$ Cfr. R. D. Freeman (1969: 173-186). 
estabilidad de la sociedad, necesaria para el ejercicio de la libertad natural, requiere de una mínima igualdad entre todos los individuos respecto a los hábitos morales.

Algunos autores han afirmado que la finalidad de esta educación subvencionada de la gente común es, en Adam Smith, la preparación de trabajadores profesionales desde una perspectiva económica ${ }^{78}$. Nosotros no coincidimos enteramente con esa opinión y sostenemos que el objetivo de esta enseñanza es en parte esa profesionalización, para la que se introduce la enseñanza de la geometría y la mecánica ${ }^{79}$; pero en otra parte no menos importante esa finalidad es moral. Hemos visto que Smith insiste en defectos de inteligencia y carácter producidos por la división del trabajo, los cuales pueden conducir a cierta inestabilidad de la sociedad libre.

A propósito de la instrucción que el público debe proporcionar a la gente común, Adam Smith habla de una verdadera educación moral y política. "Las personas inteligentes e instruidas", dice, "son siempre más razonables y disciplinadas que las ignorantes y estúpidas. Se siente, cada uno, más respetable, con más posibilidades de obtener el respeto de sus superiores legales, y ellos a su vez se encuentran mejor dispuestos a respetar a esos superiores. Están más dispuestos y son más capaces de examinar y ver a través de las parcialidades de los distintos bandos y sediciones, y a causa de esto están menos propensos a ser engañados por cualquier oposición perversa o innecesaria a las medidas del gobierno. En los países libres, en que la seguridad del gobierno depende en gran medida del juicio favorable que las personas se formen de su conducta, es de gran importancia que ellos no tengan una disposición a juzgarlo de modo irreflexivo y caprichoso" $" 80$.

Pero el hombre indigente, habituado a un trabajo simple y rutinario, "es completamente incapaz de juzgar de los amplios intereses de su país; y a no ser que se hayan realizado esfuerzos por cambiarlo, es igualmente incapaz de defender su país en la guerra. La uniformidad de su vida estacionaria corrompe naturalmente el ánimo de su mente, y le hace ver con aborrecimiento la vida irregular, incierta y aventurada del soldado. Ella corrompe aun la actividad de su cuerpo, y lo vuelve incapaz de ejercitar su fuerza con vigor y perseverancia en cualquier otro empleo que no sea aquel en que ha sido criado. Su destreza en su propio y particular oficio parece, de esta manera, ser adquirida a expensas de sus virtudes intelectuales, sociales y marciales. Sin embargo, en cualquier sociedad que haya hecho progresos,

\footnotetext{
${ }^{78}$ Cfr. Joseph Cropsey (1957: 156-158); David A. Reisman (1976: 156-158).

${ }^{79}$ Cfr. Mark Blaug (1975: 572).

${ }^{80} R N$, V.i.f.61, 788.
} 
civilizada, ése es el estado en que los trabajadores pobres, esto es gran parte de la gente, tienen que caer necesariamente, a no ser que el gobierno se esfuerce en impedirlo" 81 .

Recordemos que cuando Adam Smith denuncia los efectos perniciosos que el trabajo especializado rutinario tiene en los hombres comunes, dice que la apatía de la mente a la que sucumben los hace incapaces de gozar o compartir una conversación racional, ni de concebir o imaginar algún sentimiento generoso, noble o tierno, y por consiguiente incapaces de formar algún juicio justo respecto de los deberes ordinarios de la vida priva$\mathrm{da}^{82}$. Estos hábitos necesarios al individuo para su inserción conveniente en una sociedad civilizada y libre, establecidos por Smith en La Riqueza de las Naciones, son comprensibles a la luz del fenómeno moral de la simpatía y del espectador imparcial, que nuestro autor explica en La Teoría de los Sentimientos Morales. Nosotros aprobamos o desaprobamos la conducta de otro, dice allí Smith, de acuerdo con lo que sentimos cuando, poniéndonos imaginariamente en su caso, simpatizamos o no con los sentimientos y los motivos que lo dirigen. De la misma manera, aprobamos o desaprobamos nuestra propia conducta, según si sentimos que, cuando nos ponemos imaginariamente en la situación de otro hombre, y la vemos, por así decir, con sus ojos y desde su situación, podemos participar o no y simpatizar o no con los sentimientos y motivos que influyen en ella ${ }^{83}$.

El sentimiento de simpatía surge, por tanto, como una consideración objetiva de una situación humana particular, y de la correspondencia de los sentimientos del otro con esas circunstancias, consideración que se realiza cognitivamente. En efecto, para Smith hay una conexión lógica entre simpatizar y juzgar, ya que todo sentimiento simpatético da lugar a un juicio de aprobación o desaprobación de modo necesario, según una ley científica de asociación de ideas ${ }^{84}$. Uno es capaz de ponerse en el caso del otro, y formarse una concepción de sus sentimientos, por medio de representaciones de la imaginación ${ }^{85}$, que suscitan a su vez ciertos sentimientos en nuestro corazón ${ }^{86}$. El juicio acerca del desarrollo moral que nuestras acciones deben seguir en una determinada situación requiere, por tanto, imaginación, ya que nos tenemos que representar posibles cursos de acción, considerar los efectos de nuestras elecciones en los otros, y así ver la situación desde

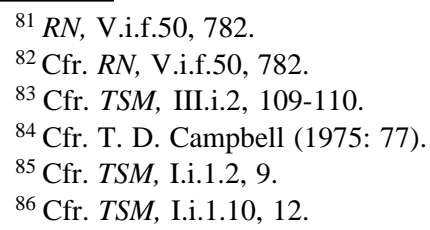


su punto de vista, y reflexionar sobre nuestras propias motivaciones desde el punto de vista del espectador imparcial ${ }^{87}$.

Como dice Griswold, explicando el pensamiento de Smith, "un sentido del deber vivo complementado por una imaginación moral que haya sido enseñada, una conciencia alerta, y el buen juicio, son esenciales para el desarrollo del sentido de la justicia, sin el cual, como insiste Smith, la sociedad colapsa porque cae en conflictos. Especialmente en los casos en que el mérito y la falta de mérito están implicados, el juicio recto es un proceso complejo. Se requiere habilidad intelectual para asimilar y examinar la información relevante, por lo que un cierto nivel intelectual es necesario para la virtud moral. Al menos se necesita captar la situación inmediata, respondiendo con las emociones correctas, comprendiendo con precisión las emociones del agente, participando en las conversaciones necesarias en que los múltiples factores son valorados y sopesados, y por cierto haciendo todo eso respecto a nosotros mismos si somos el agente que debe ser evaluado. El actor moral debe ser receptivo a la persuasión tanto como capaz de persuadir. El cultivo de la mente es así una tarea moral”88.

En esa interacción social inteligente, y moralmente solidaria, es necesario que participen todos los individuos. Cuando Adam Smith habla de los intereses sectoriales de la sociedad comercial en La Riqueza de las Naciones, se refiere a tres órdenes sociales, el de los señores de la tierra, el de los industriales y comerciantes, y el de los obreros ${ }^{89}$. Pues bien, la educación del tercer orden, que como hemos visto es una tarea moral del público, permite al sector social de más bajo rango en la sociedad moderna, que es mayoría, tener discernimiento político y capacidad para no ser engañados, evitando así disturbios provenientes del capricho. Los hace disciplinados, respetables y dispuestos a respetar a los superiores, capaces de juzgar acertadamente la conducta de los gobernantes como de juzgar de los intereses del país, y de ejercitarse en las virtudes marciales cuando sea necesario.

\section{Recapitulación}

Aunque Adam Smith haya escrito su obra más conocida — La Riqueza de las Naciones - poniendo las bases para la prosperidad económica de las naciones, y haya centrado el desarrollo de la sociedad comercial en el

${ }^{87}$ Cfr. Charles Griswold (1999: 214); una explicación más completa del fenómeno de la simpatía de acuerdo a la filosofía smithiana se puede ver en María Elton (2001-2002: 25-50).

${ }^{88}$ Charles Griswold (1999: 215).

${ }^{89}$ Cfr. RN, I.ix.5-9, 106-108. 
ejercicio del amor a sí mismo de los individuos, no tenía como ideal la práctica individual del consumismo, a lo que ha conducido el economicismo actual, ni una competencia económica fuera del marco de la justicia conmutativa. Además hace compatible en esa obra la práctica del amor a sí mismo con algunas exigencias de la benevolencia. Su esquema es ilustrado y empirista, en el cual destacan algunas virtudes distintas de la perfección humana clásica, pero que constituyen un sistema moral. Adam Smith habría criticado el economicismo actual y sus consecuencias precisamente por su falta de ética.

Para entender su pensamiento hay que profundizar en el estatuto epistemológico de La Riqueza de las Naciones, que es filosófico empirista, no científico positivista. Los equívocos provienen en gran parte de la misma ciencia económica que pretende tener a Adam Smith como padre. El trasfondo de la divergencia entre esa ciencia y la filosofía smithiana está en la interpretación diferente que hacen del pensamiento de Newton. Smith elabora La Riqueza de las Naciones teniendo como patrón metodológico las "reglas del filosofar" newtonianas, según las cuales por medio de la inducción se puede llegar a conocer las causas de los fenómenos naturales. Se trata de un proceso filosófico y creativo que Smith aplica al estudio de los fenómenos sociales, con el fin de conocer ciertos principios que expliquen la psicología humana y la integración del individuo en una sociedad que funcione éticamente. La ciencia económica positivista, en cambio, se ha centrado sólo en el momento posterior a esa metodología newtoniana, aplicando sintéticamente los principios descubiertos de forma axiomático-deductiva a los fenómenos sociales, pero sin profundizar en el aspecto humano de los principios que aplica como axiomas. Así ha puesto el énfasis en la matematización de los fenómenos económicos, que han sido considerados por ella de forma mecánica.

Esta contraposición epistemológica lleva consigo diferencias fundamentales respecto a la concepción del comportamiento del individuo en el mercado y en la sociedad. Para la ciencia económica positivista, los individuos son meros átomos en las negociaciones del mercado. Para Adam Smith, los individuos tienen una psicología moral de la que dependen acciones que mejoran o empeoran la sociedad. Smith pensaba que la prosperidad económica y política depende más de ciertas virtudes menores que forman parte de la prudencia, como la diligencia, la frugalidad y la previsión; y de una organización educacional que contrarreste las desigualdades que ponen a la gente común por debajo de ciertos niveles de formación humana, que del modelo matemático al que se pretende ajustar el comportamiento de los individuos. 
Desde esta perspectiva, el interés por sí mismo que está en la base de las actividades del mercado debe ser, según los principios smithianos, amor a sí mismo prudente y justo, que tiene como fin un acrecentamiento del capital que redunda en el aumento de las oportunidades de trabajo. El amor a sí mismo prudente, a su vez, no se opone al ejercicio de la benevolencia en la sociedad comercial. Aunque la benevolencia no es exigible legalmente en los intercambios económicos, ni en general, porque es un deber imperfecto según la tradición iusnaturalista protestante, a la que pertenece Smith, puede ser requerida como algunos comportamientos que mantengan el equilibrio social necesario para el desarrollo de la libertad natural individual. Esto se entiende si se lee La Riqueza de las Naciones a la luz de La Teoría de los Sentimientos Morales. La contemporaneidad entre dos comportamientos aparentemente opuestos se explica, por ejemplo, en el deber que tienen los gobernantes de promover la educación de la gente común, que sufre un daño intelectual y moral por la especialización del trabajo.

Hay que hilar fino para descubrir cómo se puede justificar, desde los principios de la filosofía de Adam Smith, la exigencia de actitudes benevolentes para la realización de un servicio público. Según el pensamiento smithiano, la benevolencia no se extiende por naturaleza hacia los extraños, y se ejerce de una manera puramente privada. Por otra parte, no puede ser exigida por los demás individuos como la justicia conmutativa. La justicia, que Smith entiende sólo como justicia conmutativa, es el pilar de la sociedad, mientras que la benevolencia es su embellecimiento opcional. Adam Smith es un heredero del iusnaturalismo protestante, según el cual sólo los derechos perfectos pueden ser exigidos por ley, mientras que los derechos imperfectos son sólo obligaciones morales. Así, es virtuoso ayudar al pobre, pero no es obligatorio jurídicamente.

Sin embargo, Smith deja una salida a ese esquema al afirmar en La Teoría de los Sentimientos Morales que si bien la beneficencia no puede ser impuesta por la fuerza entre iguales, puede ser exigida por la autoridad civil para restablecer un mínimo de igualdad entre los individuos que conforman una sociedad. Así concilia la justicia distributiva aristotélico-escolástica, como obligación de la comunidad representada por el gobernante, con el concepto protestante de justicia distributiva como caridad. En definitiva, aunque la justicia conmutativa sea el fundamento esencial de la vida social, la justicia distributiva, entendida como benevolencia, tiene también cierta importancia para el justo desarrollo de la sociedad civilizada.

La educación de las personas comunes es uno de los servicios públicos exigibles a la comunidad por el magistrado civil, de acuerdo con los principios smithianos. Es necesaria para paliar ciertos desequilibrios socia- 
les producidos por la división del trabajo. La tendencia natural al intercambio propia del hombre, que lleva a la división del trabajo, tiene consecuencias ventajosas para la condición humana, como señala Adam Smith en el Capítulo 1 del Libro I de La Riqueza de las Naciones, que se manifiestan en prosperidad económica y desarrollo de ciertas virtudes morales relacionadas con el trabajo, como la laboriosidad y la frugalidad, que son partes de la prudencia inferior. Pero al mismo tiempo, como dice el Libro V de la misma obra, tiene efectos deshumanizadores, porque el trabajo de la gente común se limita a unas pocas operaciones simples, que no permiten su crecimiento intelectual y moral, volviéndose apáticos, sin carácter ni capacidad de relación social. Para Smith la desigualdad de inteligencia y carácter moral entre los hombres no es fruto de la naturaleza, sino del trabajo, del cual dependen los hábitos.

Ahora bien, si esa desigualdad subsiste no puede haber paz en la sociedad, porque una gran mayoría estúpida e ignorante no es disciplinada, ni puede juzgar recta y reflexivamente acerca del gobierno, ni considerar imparcialmente los distintos bandos y sediciones, ni defender a la nación como soldado. No son capaces de adquirir ciertos hábitos por medio del ejercicio de la simpatía, ni tener sentido del deber. El desarrollo del comercio crea riqueza y proporciona trabajo independiente a todos ${ }^{90}$, a diferencia de lo que sucedía en el feudalismo, pero produce este desequilibrio social que tiene que ser subsanado para universalizar la capacidad moral y política de todos los individuos ${ }^{91}$. Para ello el Estado debe impulsar la beneficencia del público, de modo que establezca y financie escuelas en cada condado o distrito con la finalidad de que la gente común pueda desarrollar integralmente su personalidad, adquiriendo hábitos intelectuales y morales.

No estamos de acuerdo por tanto con West, quien establece una dualidad en el pensamiento de Adam Smith, por la contraposición establecida entre el Libro I y el Libro V de La Riqueza de las Naciones. Ésta se debería a que Smith habría hecho un análisis económico en el primero y uno sociológico en el segundo, por lo que tendría dos teorías alternativas sobre la división del trabajo, difícilmente reconciliables entre si ${ }^{92}$. Tampoco con Rosenberg, que discute con West afirmando que no existe tal contraposición, ya que aunque los grupos de trabajadores a los que se refiere Smith en el Libro V disminuyen su capacidad tecnológica, otros sectores sociales logran aumentarla, por la especialización, con lo que el desarrollo tecnológico, necesario para el crecimiento de la sociedad civilizada, se produce de

\footnotetext{
${ }^{90}$ Cfr. María Elton (2005: 101-110).

${ }^{91}$ Cfr. María Elósegui (1990: 439).

${ }^{92}$ Cfr. Edwin G. West (1964: 2-32).
} 
modo natural a medida que el trabajo se especializa ${ }^{93}$. Nos parece que Adam Smith proporciona una solución a la desigualdad social que origina la división del trabajo, tan beneficiosa por otra parte para el desarrollo de la civilización, permitiendo que la benevolencia sea exigida a la sociedad, en cierta medida, por el magistrado. Este quiebre en su esquema iusnaturalista, según el cual los derechos imperfectos apelarían sólo a deberes morales, y no jurídicos, redunda en una mejora del sistema de la libertad natural, que supone una igualdad moral básica entre los individuos, y muestra la pertenencia de Adam Smith a una tradición en que ética y economía se compenetran.

Como hemos dicho al comienzo de este trabajo, tras los análisis económicos y sociológicos de La Riqueza de las Naciones hay una visión moral del hombre y la sociedad, explicada en profundidad en La Teoría de los Sentimientos Morales, que vincula el desarrollo de la sociedad comercial a fuerzas morales, como son la prudencia inferior, la justicia conmutativa y cierto grado de benevolencia exigible a la sociedad para subsanar desigualdades. Como ha dicho Cropsey, el proceso civilizador no es para Smith un bien absoluto, sino que es capaz de generar grandes desórdenes sociales. La deshumanización del hombre como consecuencia de la división del trabajo es quizás lo que produce uno de los quiebres más hondos en esa evolución ${ }^{94}$. Pero Adam Smith propone una solución para remediar los efectos perversos de esa evolución social.

\section{REFERENCIAS BIBLIOGRÁFICAS}

\section{a) Abreviaciones y referencias de las obras citadas de Adam Smith}

LJ Lectures on Jurisprudence.

RN La Riqueza de las Naciones

[WN, The Wealth of Nations].

TSM

La Teoría de los Sentimientos Morales

[TMS, The Theory of Moral Sentiments].

Las referencias siguen las divisiones, párrafo(s) y página(s) de las ediciones en inglés de Liberty Fund, que son reproducciones fotográficas de las publicadas por Oxford University Press (basadas a su vez en la edición de la Universidad de Glasgow).

(LJ) Lectures on Jurisprudence. R. L. Meek, D. D. Raphael y P. G. Stein (eds.). Indianápolis: Liberty Fund, 1982 [Oxford University Press, 1978].

\footnotetext{
${ }^{93}$ Cfr. Nathan Rosenberg (1965: 127-139).

${ }^{94}$ Cfr. Joseph Cropsey (1975: 151).
} 
(RN) An Inquiry into the nature and Causes of the Wealth of Nations [WN, 1776]. Campbell y A. S. Skinner (eds.). Indianápolis: Liberty Fund, 1981 [Oxford University Press, 1976, 1979].

(TSM) The Theory of Moral Sentiments [TSM, 1759]. D. D. Raphael y A. A. Macfie (eds.). Indianápolis: Liberty Fund, 1982 [Oxford University Press, 1976, 1979].

\section{b) Otros autores citados}

Blaug, Mark: "The Economics of Education in English Classical Political Economy". En Andrew S. Skinner y Thomas Wilson (eds.), Essays on Adam Smith, Oxford: Clarendon Press, 1975.

Campbell, T. D.: "Scientific Explanation and Ethical Justification in the Moral Sentiments”. En Andrew S. Skinner y Thomas Wilson (eds.), Essays on Adam Smith. Oxford: Clarendon Press, 1975.

Cropsey, Joseph: Polity and Economy. An Interpretation of the Principles of Adam Smith. La Haya: Martinus Nijhoff, 1957.

— “Adam Smith and Political Philosophy”. En Andrew S. Skinner y Thomas Wilson (eds.), Essays on Adam Smith. Oxford: Clarendon Press, 1975.

Elósegui, María: “El Derecho del Ciudadano a la Participación en la Vida Política en Hume, Smith y la Ilustración Escocesa”. Anuario de la Filosofía del Derecho. Madrid: 1990, Tomo VII.

Elton, María: “La simpatía como causa de los juicios morales”. Philosophica, № 24-25, 2001-2202.

“Los Fundamentos de la Libertad Natural en Adam Smith”. En Paul Ludwig Weinacht y María Elton (eds.), Algunos Problemas Actuales en Filósofos Políticos Ilustrados. Santiago de Chile: Lexis Nexis, 2005.

Fleischacker, Samuel: On Adam Smith's Wealth of Nations. Princeton, Oxford, Princeton University Press, 2004.

Fitzgibbons, Athol: Adam Smith's System of Liberty, Wealth, and Virtue. Oxford, Clarendon Press, 1995.

Freeman, R. D.: “Adam Smith, Education, and Laissez Faire”. History of Political Economy, 1 (1969).

Gallego García, Elio A.: "Participación y Libertad Cívicas. Democracia y Representación desde la Perspectiva de Rousseau”. En Paul Ludwig Weinacht y María Elton (eds.), Algunos Problemas Actuales en Filósofos Políticos Ilustrados. Santiago de Chile: Lexis Nexis, 2005.

Griswold, Charles: Adam Smith and The Virtues of Enlightenment. Cambridge University Press, 1999.

Haakonssen, Knud: “Introduction”. En Adam Smith, The Theory of Moral Sentiments. Cambridge University Press, 2002.

Hont, Istvan y Michael Ignatieff: "Need and Justice in The Wealth of Nations". En Istvan Hont y Michael Ignatieff (eds.), Wealth \& Virtue: The Shaping of Political Economy in the Scottish Enlightenment. Cambridge University Press, 1983.

Lázaro, Raquel: "Un Apunte sobre el Pensamiento Moderno: La Rochefoucauld, B. Mandeville y A. Smith”. Anuario Filosófico, XXXVI/3 (2003)

Montes, Leonidas: Adam Smith in Context. Nueva York: MacMillan, 2004. 
Pieper, Josef: Las Virtudes Fundamentales. Madrid: Rialp, 1980.

Raphael, D. D. y A. L. Macfie (eds.). Introducción. En Adam Smith, The Theory of Moral Sentiments. Liberty Classics, 1982.

Reisman, David A.: Adam Smith's Sociological Economics. Londres: Croom Helm, 1976.

Rosenberg, Nathan: “Adam Smith on the Division of Labour: Two Views or One?”. Economica, 32, 1965.

Vivenza, Gloria: Adam Smith and The Classics. Oxford, University Press, 2001.

West, Edwing G.: "Adam Smith on the Division of Labour”. Economica, 31, 1964.

Young, Jeffrey: Economics as a Moral Science. Cheltenham: Edward Elgar Publishing Limited, 1997. 